\title{
MICRORREATOR CAPILAR NA SÍNTESE DE DERIVADOS DA TIAZOLIDINA-2,4-DIONA COM ALDEÍDOS ARÍLICOS: INFLUÊNCIA DA TEMPERATURA NO RENDIMENTO DO PRODUTO
}

\author{
P. V. C. CALVO ${ }^{1}$, D. S. PINHEIRO ${ }^{2}$, E. N. SANTOS ${ }^{2}$, G. CONSOLINI ${ }^{2}$, R. O. SILVA ${ }^{2}$, R. \\ O. VIEIRA ${ }^{2}$ e M. S. A. PALMA ${ }^{1}$ \\ ${ }^{1}$ Faculdades Oswaldo Cruz, Faculdade de Engenharia Química \\ ${ }^{2}$ Universidade de São Paulo, Departamento de Tecnologia Bioquímico-Farmacêutica \\ E-mail para contato: msapalma@usp.br
}

\begin{abstract}
RESUMO - A 2,4-tiazolidinadiona (TZD) e seus derivados constituem um importante grupo farmacofórico no combate de doenças como a diabete tipo melitus. Devido a aplicabilidade desses compostos é de suma importância aprimorar o processo de síntese. A utilização de microrreatores de fluxo contínuo surge como opção para melhorar as condições operacionais, já que proporciona a substancial redução de resíduos, aumentam a qualidade na transferência de massa e de calor, o que acarreta em um processo facilmente controlável permitindo maior rendimento e seletividade. Foi estudada a influência da temperatura $(78,98$, 120 e $140^{\circ} \mathrm{C}$ ) no rendimento do produto obtido da reação entre TZD com os aldeídos arílicos: benzaldeído, 4-hidroxibenzaldeído, 4-hidroxi-3metoxibenzaldeído, 4-nitrobenzalaldeído e 4-metoxibenzaldeído, utilizando etanol como solvente e piperidina como catalisador. O produto obtido em cada reação foi posteriormente purificado por cristalização e recristalização com etanol. A quantificação da TZD, aldeídos e produtos formados foi realizada por HPLC-UV. Determinou-se que o rendimento do produto cresce com o tempo espacial e temperatura no microrreator e obteve-se um rendimento máximo de 70,9\%, para o derivado da TZD com 4-metoxibenzaldeído e tempo espacial 20 min. Constatouse um aumento de 10 vezes no rendimento do derivado com 4-nitrobenzaldeído com o aumento da temperatura de 78 para $140^{\circ} \mathrm{C}$, que chegou a $35,8 \%$ para tempo espacial $20 \mathrm{~min}$.
\end{abstract}

\section{INTRODUÇÃO}

A 2,4-tiazolidinadiona (TZD) é um grupo farmacofórico importante presente em fármacos utilizados no combate a doenças e está presente no fármaco comercial Pioglitazona ${ }^{\circledR}$. Os derivados das tiazolidinadionas são produtos com atividade hipoglicemiante que reduzem a resistência à insulina sistêmica pelos tecidos periféricos (Jain et al., 2013). Visto que a TZD apresenta diferentes atividades biológicas, houve um grande incentivo aos químicos para fazerem modificações nesta molécula e utilizá-la na síntese de compostos com atividades farmacológicas e terapêuticas importantes (Mohanty et al., 2015) COMO anticancerígena, anti-HIV, anti-convulsionante, antimicrobiana, anti-histamínica, 
anti-hipoglicêmica (diabetes melitos), antifúngica, amebicida, anti-inflamatória, entre outros (Lima, 1998; Bahare et al., 2015). A Figura 1 apresenta a estrutura molecular da TZD.

Figura 1 - Estrutura molecular da 2,4-tiazolidinadiona (TZD).<smiles>O=C1CSC(=O)N1</smiles>

O processo de síntese consiste na reação entre um composto carboxílico que não possua um $\mathrm{H}$ ácido e um composto que contenha grupo metileno ativado, formando um aduto com uma ligação dupla carbono-carbono $(\mathrm{C}=\mathrm{C})$. O mecanismo da reação, esquematizado na Figura 2, se dá por duas etapas essenciais, sendo a primeira a adição nucleofílica à carbonila e a segunda a eliminação de uma molécula de água, ocorrendo a formação de ligação $\mathrm{C}=\mathrm{C}$ (Cunha e Santana, 2012).

Figura 2 - Mecanismo geral para a síntese de derivados da TZD.

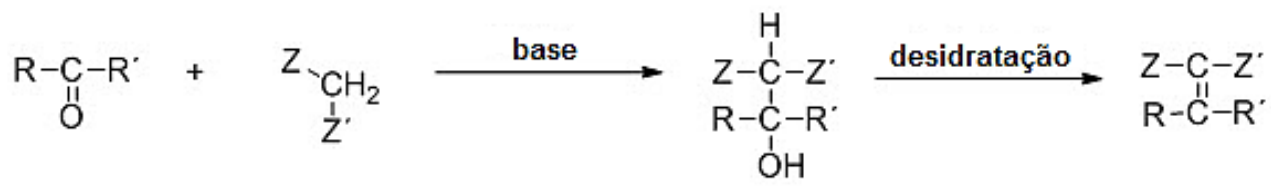

Devido a sua aplicabilidade na indústria farmacêutica é de suma importância aprimorar a síntese desses compostos. A utilização de microrreatores nas indústrias químicofarmacêuticas proporciona a redução do impacto gerado pelos processos com substancial redução de resíduos sendo uma das principais vantagens deste tipo de equipamento a velocidade com que a mistura dos reagentes ocorre devido à pequena distância entre os microcanais dentro do suporte. Além disso, eles proporcionam um aumento de qualidade expressiva na transferência de massa e de calor, o que acarreta em um processo facilmente controlável permitindo maior rendimento e seletividade, já que os microrreatores inibem reações paralelas, o que não ocorre em reatores de batelada (Watts e Wiles, 2012).

Figura 3 - Equipamentos (A), (B), (C) e (D) utilizados na síntese dos derivados da 2,4-tiazolidinadiona.

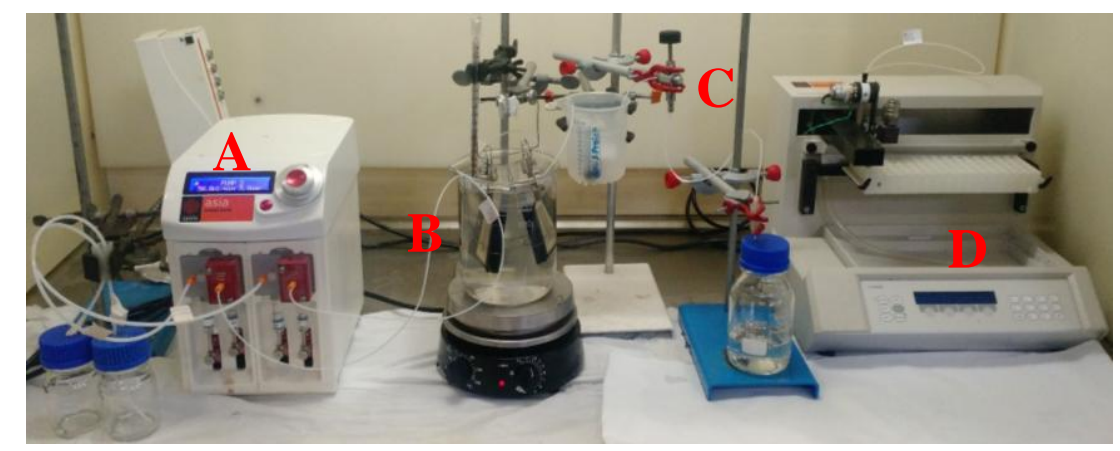

Na Figura 3 estão mostrados o sistema de bombeamento de dois canais do tipo seringa e pistão, além dos frascos reagentes para inserção do produto no microrreator (A), os 
microrreatores de vidro acoplados ao chip header e que estão imersos no sistema de aquecimento (B), o regulador de pressão (C) e o sistema de coleta automática de amostras (D).

\section{MATERIAIS E PROCEDIMENTO EXPERIMENTAL}

\subsection{Materiais}

Na síntese dos derivados da 2,4-tiazolidinadiona são utilizados TZD, benzaldeído, 4hidroxibenzaldeído, 4-hidroxi-3-metoxibenzaldeído (Vanilina), 4-nitrobenzalaldeído e 4metoxibenzaldeído (Anisaldeído), como reagentes; etanol $(99,8 \% \mathrm{~m} / \mathrm{m})$ como solvente no meio reacional, piperidina como catalisador e etanol $(99,5 \% \mathrm{~m} / \mathrm{m})$ no work-up do produto que consiste de cristalização e recristalização. Utiliza-se, quando necessário, água destilada.

\subsection{Procedimento Experimental}

O processo de síntese no microrreator consiste em, primeiramente, preparar duas soluções de alimentação. Para o preparo da primeira solução, solubilizou-se 4 mmol de TZD e $3,2 \mathrm{mmol}$ piperidina em $30 \mathrm{~mL}$ de etanol $99,8 \%$. No preparo da segunda solução, solubilizouse $4 \mathrm{mmol}$ do respectivo aldeído em $30 \mathrm{~mL}$ de etanol 99,8\%. Posteriormente, as duas soluções previamente preparadas foram alimentadas separadamente ao microrreator na vazão e temperatura adequada. Para o processo de síntese foram empregadas as temperaturas de 78, 98, 120 e $140^{\circ} \mathrm{C}$, e foram realizadas amostragens para tempos médios de residência (tempo espacial, $\tau)$ de 2, 4, 12 e 20 minutos. O produto sólido obtido nas reações foi posteriormente purificado por cristalização e recristalização com etanol 99,5\%. A quantificação da TZD, dos aldeídos e dos produtos formados foi realizada por HPLC-UV e o método foi adaptado de Gumieniczek et al. (2010).

\section{RESULTADOS E DISCUSSÕES}

Os resultados de rendimento do produto em função do tempo espacial cada aldeído nas temperaturas de $78,98,120$ e $140^{\circ} \mathrm{C}$ estão apresentados nas Figuras 4, 5, 6 e 7.

Figura 4 - Rendimentos de produtos obtidos na temperatura de $78^{\circ} \mathrm{C}$.

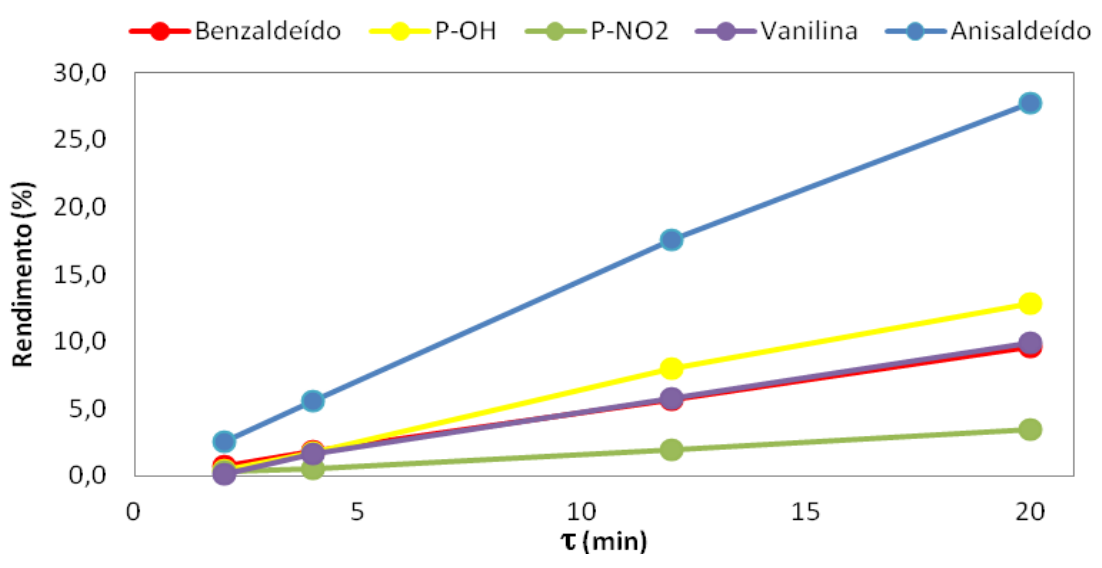


A Figura 4 mostra que o rendimento do produto cresce com o tempo espacial para os 5 aldeídos estudados e que o maior rendimento foi obtido na síntese do derivado da TZD com anisaldeído (27,8\% para $\tau=20 \mathrm{~min})$. O pior resultado foi obtido na síntese do derivado com 4nitrobenzaldeído (3,5\% para $\tau=20 \mathrm{~min}$ ). As reações da TZD com benzaldeído e 4-hidroxi-3metoxibenzaldeído (vanilina) apresentaram resultados muito próximos de 9,6 e 9,9\% respectivamente. A reação da TZD com 4-hidroxibenzaldeído apresentou rendimento de $12,8 \%$ para $\tau=20 \mathrm{~min}$.

Figura 5 - Rendimentos de produtos obtidos na temperatura de $98^{\circ} \mathrm{C}$.

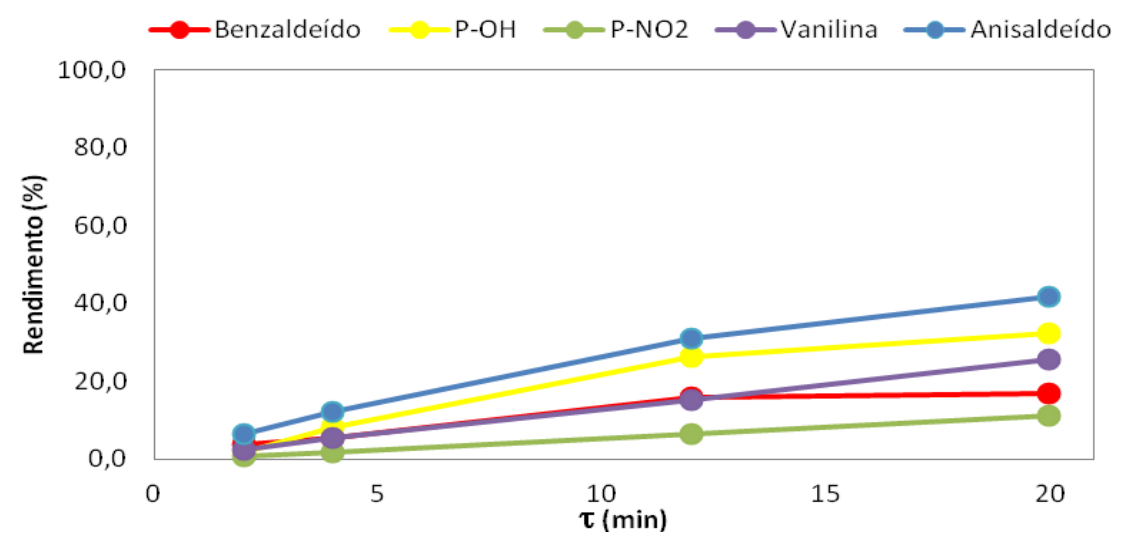

$\mathrm{Na}$ temperatura de $98^{\circ} \mathrm{C}$ o maior rendimento de produto foi obtido na reação com 4metoxibenzaldeído (anisaldeído) (41,6\% para $\tau=20 \mathrm{~min}$ ), os aldeídos que apresentaram os piores resultados foram o 4-nitrobenzalaldeído $(11,1 \%)$ e o benzaldeído $(16,8 \%)$. Os aldeídos 4-hidroxi-3-metoxibenzaldeído (vanilina) e 4-hidroxibenzaldeído apresentaram rendimentos de 25,4 e $32,2 \%$, respectivamente, para $\tau=20 \mathrm{~min}$.

Figura 6 - Rendimentos de produtos obtidos na temperatura de $120^{\circ} \mathrm{C}$.

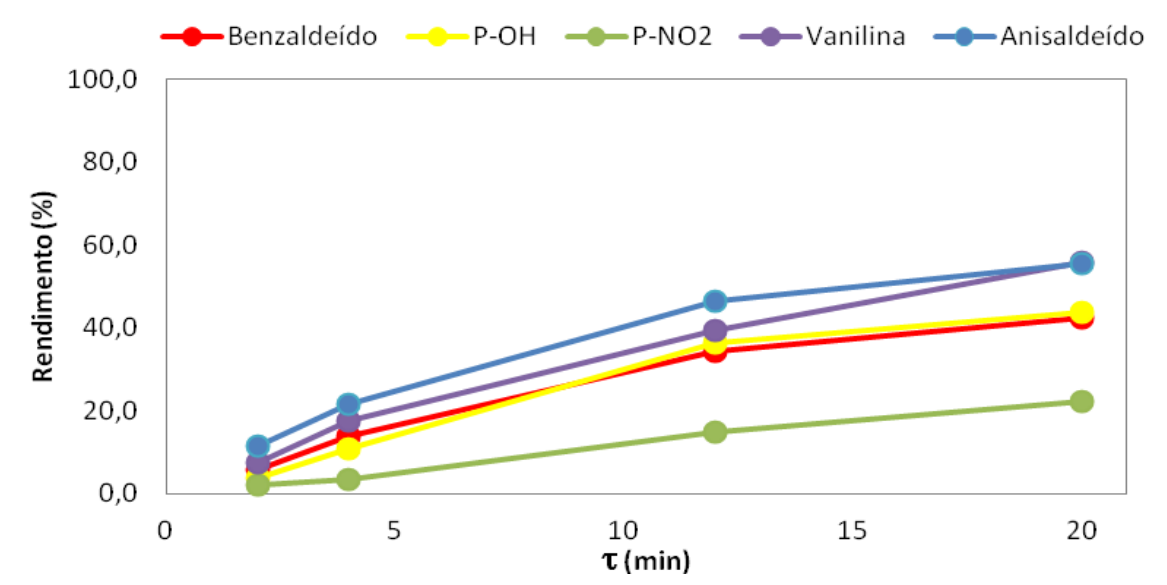

A Figura 6 mostra que as reações envolvendo o 4-metoxibenzaldeído (anisaldeído) e o 4-hidroxi-3-metoxibenzaldeído (vanilina) apresentaram os melhores resultados, sendo eles respectivamente, 55,4 e 56\%. O benzaldeído e o 4-hidroxibenzaldeído apresentaram 
rendimentos muito próximos para $\tau=20 \mathrm{~min}, 42,5$ e 43,7\%, respectivamente. O menor rendimento foi observado para o 4-nitrobenzalaldeído (22,3\%).

Figura 7 - Rendimentos de produtos obtidos na temperatura de $140^{\circ} \mathrm{C}$.

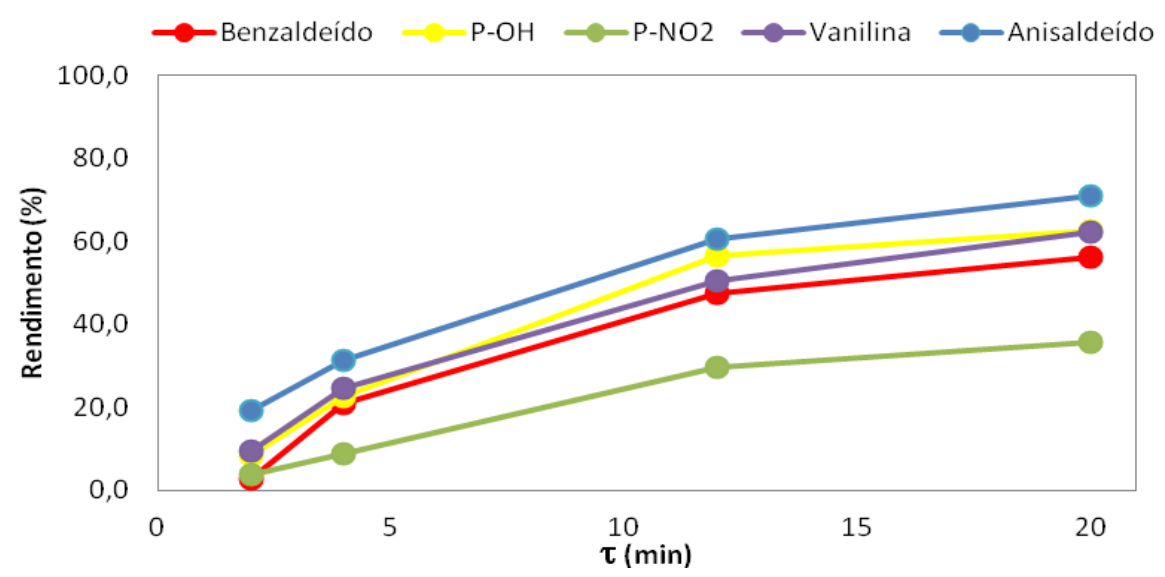

A Figura 7 mostra que o 4-metoxibenzaldeído (anisaldeído) apresentou o melhor resultado (70,9\% para $\tau=20 \mathrm{~min}$ ). Os aldeídos 4-hidroxibenzaldeído e 4-hidroxi-3metoxibenzaldeído (vanilina) apresentaram valores muito próximos sendo eles, respectivamente, 62,5 e $62,3 \%$. O benzaldeído apresentou $56,25 \%$ para $\tau=20$ min. O 4nitrobenzalaldeído apresentou o pior rendimento $\tau=20 \min (35,8 \%)$.

As Figuras 4 a 7 mostram a mesma tendência de crescimento do rendimento do produto com a temperatura para os 5 aldeídos estudados. Este fato evidencia que a escala de reatividade os aldeídos com TZD tem a seguinte sequência: anisaldeído > 4hidroxibenzaldeído > vanilina > benzaldeído > 4-nitrobenzaldeído. Aparentemente as reações estudadas tem a mesma influência da temperatura e, desta forma, as energias de ativação das reações teriam valores semelhantes. $\mathrm{O}$ aumento da temperatura de 78 para $140^{\circ} \mathrm{C}$ provocou o maior aumento relativo de rendimento de produto para o 4-nitrobenzaldeído, cujo aumento foi de cerca de 10 vezes. Para os demais aldeídos os aumentos relativos de rendimento foram de 6,3, 5,8, 4,9 e 2,5 vezes para a vanilina, benzaldeído, 4-hidroxibenzaldeído e anisaldeído, respectivamente.

\section{CONCLUSÕES}

Nas condições estudadas a temperatura de $140^{\circ} \mathrm{C}$ apresentou os melhores resultados. Com o aumento da temperatura, maior será a interação molecular, velocidade de reação e, consequentemente, aumentará o rendimento do produto obtido. Em relação aos aldeídos, a influência da temperatura foi maior para o 4-metoxibenzaldeído (anisaldeído), apresentando os melhores valores de rendimento ao final de 20 min de reação, seguido pelos aldeídos 4hidroxibenzaldeído, 4-hidroxi-3-metoxibenzaldeído (vanilina) e benzaldeído, que com o aumento da temperatura também apresentaram melhoras significativas nos resultados. A influência da temperatura foi maior para o 4-nitrobenzalaldeído. 


\section{REFERÊNCIAS}

BAHARE, R. S.; GANGULY, S.; CHOOWONGKOMON, K.; SEETAHA, S. Synthesis, HIV-1 RT inhibitory, antibacterial, antifungal and binding mode studies of some novel Nsubstituted 5-benzylidine-2,4-thiazolidinediones. DARU Journal of Pharmaceutical Sciences, v. 23:6, p. 1-15, 2015.

CUNHA, S.; SANTANA, L. L. B. Condensação de knoevenagel de aldeídos aromáticos com o ácido de meldrum em água: uma aula experimental de química orgânica verde. Quim. Nova, v. 35, n. 3, p. 642-647, 2012.

JAIN, V.S.; VORA, D.K.; RAMAA, C.S. Thiazolidine-2,4-diones: Progress towards multifarious applications. Bioorganic \& Medicinal Chemistry, v.21, p.1599-1620, 2013.

GUMIENICZEK, A.; KOMSTA, L. Stability-Indicating Validated HPLC Method for Simultaneous Determination of Oral Antidiabetic Drugs from Thiazolidinedione and Sulfonylurea Groups in Combined Dosage Forms. JOURNAL OF AOAC INTERNATIONAL, v.93, n.4, p.1086-1092, 2010.

LIMA, J. G. Alguns Aspectos Químicos do Anel 2,4-tiazolidinadiona. Rev. Uni. Rural, Sér. Ciênc. Exatas e da Terra, v. 20, p. 1-8, 1998.

MOHANTY, S.; REDDY, S.G.; RAMADEVI, B.; KARMAKAR, A.C. Na assembly of structurally diverse small and simple 5-aminomethylene derivatives of 2,4thiazolidinedione and studies of their biological activity. Medicinal Chemistry Research, v.24, p.4037-4049, 2015.

WILES, C.; WATTS, P. Continuous flow reactors: a perspective. Green Chemistry, v. 14, p. 38-54, 2012. 